\title{
PREVALÊNCIA DE CÁRIE DENTAL EM UMA POPULAÇÃO DE ESCOLARES DA REGIÃO AMAZÔNICA
}

\author{
Antonio David Corrêa Normando* \\ Izamir Carnevali de Araújo*
}

NORMANDO, A. D. C. \& ARAÚJO, I. C. de Prevalência de cárie dental em uma população de escolares da região amazônica. Rev. Saúde públ., S.Paulo, 24 : 294-9, 1990.

RESUMO: Considerando-se a ausência de dados sobre a prevalência de cárie dental em uma populaçăo tipicamente amazônida, foi feito um levantamento epidemiológico em 103 escolares na região da Illha de Sirituba, no Município de Abaetetuba, Estado do Pará, Brasil. O CPOD médio encontrado foi de 6,5 e o ceo de 5,4. Apesar da primitividade do local, o alto índice de cárie pode estar relacionado a diversos fatores, dentre os quais deve ser incluída a influência urbana na alimentação, principalmente pelo açúcar, criando novos hábitos alimentares que alteraram fundamentalmente a dieta da região.

DESCRITORES: Cárie dentária, epidemiologia. Indice CPO. Dieta cariogênica.

\section{INTRODUÇÃO}

Os levantamentos epidemiológicos sobre cárie dental têm merecido consideracões e investigaçōes em nível universal, dada a importância que os estudos deste cunho têm com referência a implantação de sistemas de prevenção e tratamento.

Os dados obtidos no Brasil, além de serem em número reduzido, estão em geral situados restritamente às zonas urbanas dos municípios do Estado de São Paulo, além do que os pouquíssimos existentes na região Norte são obtidos em áreas urbanas ou indígenas, não caracterizando, portanto, a prevalência desse problema em áreas típicas da região Amazônica.

A Amazônia, com sua área geográfica de grandes dimensões, apresenta características e nuances diferenciadas dentro da própria região. Dessa forma, existem áreas com traços culturais íntegros, caracterizados por alguns poucos grupos indígenas isolados, e outras que sofreram processo de aculturação com zonas urbanas, devido principalmente ao comércio de produtos do extrativismo vegetal, exploração mineral e grandes projetos econômicos, áreas essas que atualmente compõem a maior parte da região,e que preocupam os mais diferentes campos da ciência.
A ilha de Sirituba, localizada em plena região amazônica, em sua maior parte às margens do rio Tucumanduba e de seus furos e igarapés, é uma área a sudoeste de Belém, próxima à desembocadura do rio Tocantins na Baia de Marajó, que preserva uma certa integridade cultural, muito embora já sofra influência marcante do meio urbano. Sob o ponto de vista estritamente odontológico,essa influência relaciona-se às mudanças nos hábitos alimentares, com conseqüente consumo do açúcar industrializado pela população local.

Parece ser aceito um conceito geral de que a cárie dental está presente e com índices alarmantes em todas as regióes estudadas no Brasil. No Estado de São Paulo, onde os levantamentos são em maior número, as frequências são variáveis, dependendo de alguns fatores, entre os quais, e que talvez seja o de principal importância, é o fato do município receber ou não tratamento da água de abastecimento público com flúor; nesse caso as reduções no índice de cárie, após anos de fluoretação, oscilam entre 40 e $65 \% 17,30,31$.

Embora a maior parte dos levantamentos de cunho epidemiológico centrem-se no Estado de São Paulo, todas as outras regiōes, tais como, a Sul $10,15,16,23$, Nordeste $8,16,26$, Centro-Oeste ${ }^{16,24}$, Norte, 16 e a própria região Sudeste, zona urbana $1,3,5,6,9,16,18$,

* Departamento de Odontologia Sanitária da Faculdade de Odontologia da Universidade Federal do Pará. Campus Universitário Guamá - 66050 - Belém, PA - Brasil. 
$20,21,22,27,28,29$ e rural 2,4 , revelam altos índices de cárie.

Estudos sobre a prevalência de cárie em indígenas brasileiros, que vivem sem grandes contatos com a população civilizada, mostram, na dentição permanente, resultados semelhantes a áreas com alto teor de flúor na água de abastecimento público. Na dentição decídua observa-se um alto índice de cárie ${ }^{13,19,25}$. As necessidades de tratamento odontológico nessas áreas, em termos relativos, são semelhantes a outras zonas rurais do país. Essas necessidades, em crianças brasileiras, mostram-se de forma geral, bastante elevada na dentição decídua em escolares de nível sócioeconômico mais baixo (escolas públicas) e na zona rural (Fig.).

Dados epidemiológicos sobre cárie dental na região Norte ainda são raridades, mesmo na zona urbana, e alguns poucos levantamentos existentes são obtidos por alunos das faculdades de odontologia da região através de trabalhos de conclusão de curso, não publicados.

Brandão (1985)*, em um estudo sobre prevalência de cárie em dentes decíduos de crianças entre 3-6 anos de idade, em uma escola da rede particular de ensino, no centro de Belém,encontrou um ceo médio de 1,8 aos 3 anos de idade e de 3,8 aos 6 anos de idade. Rabelo e Capelasso (1985)**,em um levantamento sobre a prevalência de cárie dental em primeiros molares permanentes, sem dúvida os dentes onde ocorre a maior incidência de cárie dental, observaram em alunos de uma escola pública de um bairro da periferia de Belém, os seguintes CPODs médios nas idades de 7, 8, 9 e 10 anos: 2, 63; 2,$28 ; 2,93$ e 3,33 , respectivamente, média de 2,94 .

Dados recentes, publicados pelo Ministério da Saúde ${ }^{16}$, evidenciam o alto índice de cárie dental na zona urbana da região Norte. Os resultados obtidos nas cidades de Belém e Manaus, as duas maiores da região, revelam CPOD médio de 3,1 aos 7 anos e de 7,49 aos 12 anos de idade.

$O$ presente estudo tem por objetivo apresentar um levantamento epidemiológico de cárie dental em escolares de uma região tipicamente amazônica, suprindo uma lacuna evidente na literatura, possibilitando dessa forma, o conhecimento do problema e a relação com causas, para que se viabilize a implantação de métodos de pre- venção e tratamento, evitando-se os efeitos.

\section{MATERIAL E MÉTODO}

A amostra utilizada constou de 103 escolares da faixa etária compreendida entre 7 e 14 anos completos, sendo 51 do sexo masculino e 52 do sexo feminino, matriculados na Escola Estadual de Primeiro Grau Prof. Raimundo José e Escola Municipal de Primeiro Grau $N^{a} \mathrm{Sr}^{\mathrm{a}}$. de Lurdes, ambas às margens do rio Tucumanduba na ilha de Sirituba, Município de Abaetetuba, no Estado do Pará(Tabela 1). A amostra representa a totalidade dos escolares freqüentadores das duas escolas e pode ser considerada típica das crianças habitantes na região da ilha. Este número relativamente pequeno deve-se principalmente à grande dispersão populacional na região e à distância considerada de outras escolas, além da grande evasão escolar.

O método de exame foi direto com um examinador e um anotador previamente treinados para identificação e registro dos dados obtidos, durante o exame clínico, em fichas individuais.

O exame buco-dental foi realizado com espelhos planos e exploradores $n^{2} 5$, sob iluminação natural. A avaliação da prevalência da cárie dental foi feita de acordo com os índices CPOD, de Klein e Palmer (1937) ${ }^{14}$, e ceo de Gruebbel (1944) ${ }^{11}$, com a seguinte modificação: não foi feito distinção entre os dentes cariados e os dentes cariados com extração indicada, sendo que este fato não altera a somatória computada no CPOD e ceo.

Os critérios usados no exame para considerar um dente como cariado são aqueles apresentados por Chaves (1977)?

\section{RESULTADOS}

Em toda amostra estudada (103), nenhum escolar relatou ter recebido qualquer tipo de tratamento odontológico durante toda a sua vida. Esses dados podem ser confirmados pela constatação que nenhum dente foi encontrado nos eventos "Obturado (0)" ou "Perdido (P)". Como nenhuma diferenciação foi feita entre dente cariado (C) e cariado com extração indicada ( $E \mathrm{i})$, os índices CPOD e ceo (dente cariado, perdido ou obturado) resume-se apenas a dentes cariados.

A Tabela 2 ilustra a média de dentes cariados e

BRANDÃO, A. M. M. Incidência de cárie dental em pré-escolares de 3 a 6 anos em escola particular. Estudo comparativo. Belém, Universidade Federal do Pará, 1985. [Dados inéditos].

* * RABELO e CAPELASSO, M. D. Estudo da prevalência de cárie dental em primeiros molares permanentes na Escola Almirante Tamandaré nos anos de 1983 e 1985. Belém, Universidade Federal do Pará, 1985 [Dados inéditos]. 


\section{TABELA 1}

Distribuição dos escolares, de acordo com o sexo e a idade, da primeira a quarta série do Primeiro Grau de escolas estaduais da Ilha de Sirituba, Ábaetetuba-PA, 1987

\begin{tabular}{lrrrrrrrrrr}
\hline & \multicolumn{8}{c}{ Idade (anos) } & \\
\cline { 2 - 9 } Sexo & 7 & 8 & 9 & 10 & 11 & 12 & 13 & 14 & Total \\
\hline Masc & 10 & 7 & 3 & 9 & 4 & 9 & 4 & 5 & 51 \\
Fem. & 12 & 10 & 4 & 8 & 4 & 6 & 1 & 7 & 52 \\
Total & 22 & 17 & 7 & 17 & 8 & 15 & 5 & 12 & 103 \\
\hline
\end{tabular}

\section{TABELA 2}

Indices ceo e CPOD e número médio de dentes permanentes hígidos e irrompidos de acordo com a idade em escolares da ilha de Sirituba - Abaetetuba-PA, 1987

\begin{tabular}{|c|c|c|c|c|c|c|c|c|c|}
\hline \multirow[b]{2}{*}{ Evento } & \multicolumn{8}{|c|}{ Idade (anos) } & \multirow[b]{2}{*}{$\bar{x}$} \\
\hline & 7 & 8 & 9 & 10 & 11 & 12 & 13 & 14 & \\
\hline $\begin{array}{l}\infty \circ \\
\text { CPOD } \\
\text { Hígido } \\
\text { Dentes Irrromp. }\end{array}$ & $\begin{array}{l}7,1 \\
3,4 \\
4,0 \\
7,4\end{array}$ & $\begin{array}{r}7,6 \\
3,7 \\
6,7 \\
10,4\end{array}$ & $\begin{array}{r}5,1 \\
4,7 \\
10,4 \\
15,1\end{array}$ & $\begin{array}{r}6,1 \\
5,0 \\
9,1 \\
14,1\end{array}$ & $\begin{array}{r}3,7 \\
7,0 \\
10,8 \\
17,8\end{array}$ & $\begin{array}{r}1,0 \\
7,7 \\
13,7 \\
21,0\end{array}$ & $\begin{array}{l}\overline{14,6} \\
13,2 \\
27,8\end{array}$ & $\begin{array}{l}1 \overline{13,9} \\
14,0 \\
27,9\end{array}$ & $\begin{array}{r}5,4 \\
6,5 \\
8,8 \\
15,3\end{array}$ \\
\hline
\end{tabular}

hígidos nas diferentes idades. Uma análise dessa tabela mostra $o$ aumento do número de dentes permanentes cariados de acordo com a idade.

Essa tabela mostra ainda os resultados obtidos na dentição temporária, nas idades de 7 aos 12 anos. Os individuos com 13 e 14 anos foram retirados do cômputo geral, visto não apresentarem dentes decíduos.

Um inquérito índividual, a respeito de alguns aspectos sobre a utilização de escovas dentais pela amostra estudada, embora não seja proposição deste trabalho, revelou que $16 \%$ das crianças não escovam os dentes porque naxo têm escova dental e dos $84 \%$ restantes que escovavam, $85 \%$ o faziam apenas pela parte da manhã.

\section{DISCUSSÃO}

Vários fatores, inerentes à região, devem ser levados em consideração antes de uma análise dos resultados obtidos. $O$ principal deles, sem dúvida, é a presença do açúcar como componente da dieta; $100 \%$ das crianças relataram incluir o açúcar na alimentação. Muito embora a população mantenha aspectos culturais íntegros, dentre os quais hábitos típicos de alimentação, tais como peixe, camarão, farinha de mandioca e o açaí (Euterpe oleraceu); este último é consumido em forma líquida, sem açúcar durante as refeições. Porém já existe um processo de aculturação considerável que pode ser comprovado pela presença de outros ali- mentos, tais como arroz, feijão e o próprio açúcar, todos originários dos centros urbanos.

O levantamento do problema cárie dental comprova a influência dos hábitos urbanos na alimentação. Nos resultados obtidos pelo Ministério da Saúde ${ }^{16}$, nas cidades de Belém e Manaus, os CPODs médios encontrados foram de 3,10 aos 7 anos de idade e de 7,49 aos 12 anos, e são extremamente semelhantes aos observados no presente estudo, respectivamente 3,4 e 7,7 aos 7 e 12 anos ( $\mathrm{Ta}-$ bela 2), e que por sua vez são maiores que aqueles encontrados em indígenas da região ${ }^{13,19,25}$.

A análise dos resultados mostra ainda um CPOD relativamente alto em todas as idades ( $\mathrm{Ta}$ bela 2) e semelhante a outras áreas do Brasil que năo possuem águas fluoretadas. $\mathrm{Na}$ dentição decídua, o panorama não poderia ser diferente e mostra-se de forma agravada, visto que o ceo médio encontrado nas idades de 10,11 e 12 anos é relativamente maior que em outras regióes (Tabela 2), sendo este fato um reflexo do acúmulo das necessidades de tratamento (Fig.). Esse aspecto é observado também em populaçōes índigenas ${ }^{13,25}$.

A necessidade de tratamento encontrada, tanto na dentição permanente como na decídua, foi de $100 \%$ e reflete a imprescindível urgência da implantação de sistemas de tratamento e prevenção da cárie dental. Esse quadro, embora mostrado de maneira agravada, pode ser considerado semelhante ao restante do país (Fig. ). 
** Florianópolis $(\mathrm{SC})^{23}$

arasília (DF) ${ }^{24}$

Américo Brasiliense (SP)

Xingú $^{13}$

Guaira (SP) 6

Penápolis $(\mathrm{SP})^{22}$

bBrasília (DF)24

Niterói $(\mathrm{RJ})^{3}$

Florianópolis $(S C)^{15}$

Valparaiso $(S P)^{21}$

General Salgado (SP)20

* Bauru (SP) 5

Presidente Prudente (SP) ${ }^{1}$

- Bauru (SP) 4 (7-12a)

* Araçatuba (SP) ${ }^{2}$

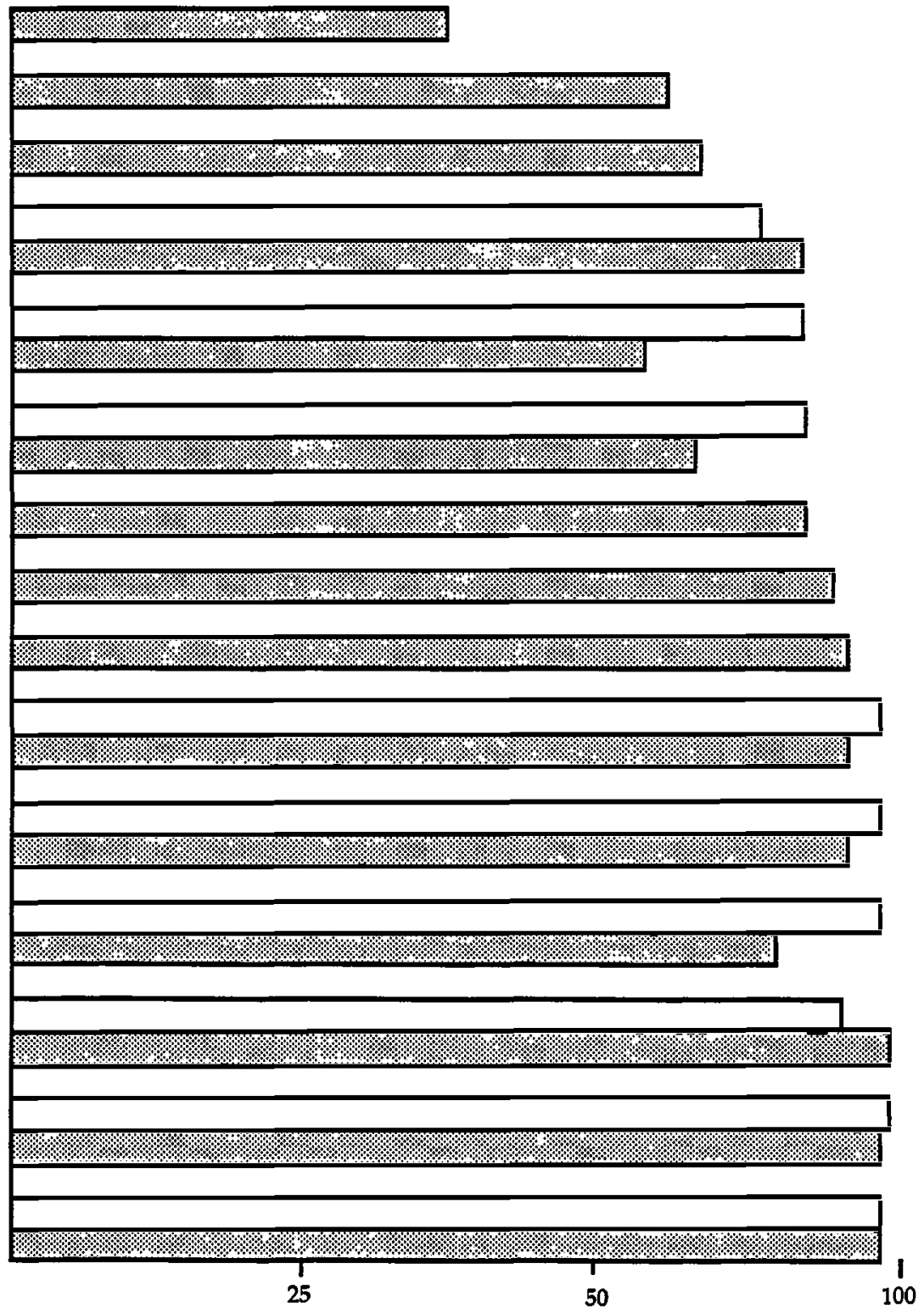

Necessidades de Tratamento (\%)

* Zona rural

- Escola particular

a Plano Piloto e Planaltina

b Gama e Taguatinga

Fonte: Dados extraídos das citações indicadas pelos respectivos números de referência, constantes em cada cidade supramencionada.

Fig. - Necessidades de tratamento $(C+E i)$ na dentição permanente aos 12 anos de idade (barra preta) e na dentição decídua aos 7 anos (barra branca). 
A alta prevalência encontrada permite incluir essa área da Amazônia como uma região com altos índices de cárie dental, segundo os parâmetros da Organização Mundial de Saûde que considera como índices altos de prevalência, aqueles que ultrapassam os valores de 6,6 (CPOD) aos 12 anos de idade (Heloe e Hangerjorden, 1981) ${ }^{12}$.

Embora a extrapolação destes resultados para o restante da regiāo pareça ser obscura, não existe motivo para se acreditar que de uma forma geral outras áreas da Amazônia apresentem resultados diferentes dos encontrados no presente trabalho, principalmente verificando-se a grande invasão urbana nos costumes regionais; no entanto, esse parece ser um farto campo para futuras investigaçðes.

\section{CONCLUSÕES}

Analisando os resultados obtidos parece lícito concluir que:

1) O CPOD médio, na amostra estudada, de 6,5 o ceo de 5,4 podem ser considerados bastante altos, quando comparado aos parâmetros da Organização Mundial de Saúde.

2) O fato de não ter sido encontrado nenhum dente obturado ( 0 ) ou extraído (E) reflete a completa ausência de tratamento odontológico nessa população e a inexistência de métodos preventivos e curativos utilizados para controlar a incidência da cárie dental na região.

NORMANDO, A. D. C. \& ARAUJO, I. C. de [ Prevalence of dental caries in a school population of the amazonian region]. Rev. Saúde públ., S.Paulo, 24: 294-9,1990

ABSTRACT: In view of the lack of data as to the prevalence of dental caries among typical amazonian populations, the authors carried out an epidemiological study of 103 schoolchildren from Sirituba Island, Abaetetuba, Pará, Brazil. The mean values found for DMFT and deft were 6.5 and 5.4 respectively. Although the region is very primitive, this high prevalence may be linked to several factors, among which is the urban influence, mainly through the use of sugar, on food habits in such a way as fundamentally to alter the diet of the amazonian population.

KEYWORDS: Dental caries, epidemiology. DMF Index. Diet, cariogenic.

\section{REFERÊNCIAS BIBLIOGRÁFICAS}

1. ABBUD, R. \& ROCCA, R. A. Prevalência de cárie em escolares da cidade de Presidente Prudente - SP. Rev. Fac. Farm. Odont. Araraquara, 7: 25-40, 1973.

2. ANDRIONI, F. N. et al. Prevalência de gengivite e de cárie dental: estudo comparativo realizado em escolares brasileiros, brancos da zona rural de Araçatuba. Rev. bras. Odont., 26: 5-10, 1969.

3. BASTOS, J. R. de M. \& FURLONI, M. G. S. R. Prevalência de cárie dentária entre 453 escolares de 7 12 anos de idade, de escolas públicas municipais. Rev. gaúcha Odont., 27: 261-3, 1979.

4. BIJELlA, M. F. T. B. \& BIJELlA, V. T. Prevalência de carie dental em escolares da zona rural de 12 municípios da região de Bauru. Rev. bras. Odont., 27: 133-8, 1970.

5. BORRO, M. F. T. T. \& BIJELLA, V. T. Prevalência de cárie dental em escolares da zona rural de Bauru. Estomat. e Cult., 3:69-76, 1969.

6. CAMPANELLA, S. \& CICIARELLI, J. R. R. Análise dos dados de prevalência da cárie dental na cidade de Guaíra - SP, Brasil, em 1710 escolares de ambos o sexos segundo a idade. Rev. Ass. paul. cirurg. Dent., 31: 313-22, 1977.
7. CHAVES, M. M. Problemas. In: Chaves, M. M. Odontologia social. $2^{2}$ ed. Rio de Janeiro, Labor, 1977. p. 23-98.

8. DINYS, Y. Inquérito dentário em escolares de algumas localidades do leste e nordeste brasileiro. Rev. Odont. Estomat., 2: 51-4, 1961.

9. FRANKEL, J. M. \& CHAVES, M. M. A utilização de um método simples de inquérito para avaliação da prevalência de cárie dental em 3009 crianças brasileiras. Rev. bras. Odont., 13: 84-105, 1955.

10. GRANDO, V. C. Prevalência de cárie dentária em primeiros molares permanentes de 684 escolares de 7 aos 12 anos de idade da zona rural da Tha de Santa Catarina . Odont. mod., 12: 8-14, 1985.

11. GRUEBBEL, A. O. A measurement of dental caries prevalence and treatment services for deciduos teeth. J. dent. Res., 23: 163-8, 1944.

12. HELOE, L. A. \& HAUGEJORDEN, O. "The rise and fall" of dental caries: some global aspects of dental caries epidemiology. Community Dent. oral Epidem., 9: 294-9, 1981. 
13. HIRATA, J. M. et al. Estudo da prevalência de cárie em crianças indígenas do Parque Nacional do Xingu. Rev. Fac. Odont. Univ. S. Paulo, 15: 18998, 1977.

14. KLEIN, H. \& PALMER, C. E. Dental caries in American indian children. Publ. Hlth Bull.,(239), 1937.

15. MAKOWIECKI, N. \& SILVA, R. H. H. da. Prevalência de cárie dentária em 277 escolares, alunos

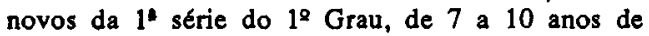
idade, ambos os sexos, de 35 escolas públicas localizadas na zona rural da regiāo da Grande Florianópolis, Estado de Santa Catarina. Rev. catar. Odont. 8:26-31, 1981.

16. MINISTÉRIO DA SAUDE. Secretaria Nacional de Programas Especiais de Saúde. Divisão Nacional de Saúde Bucal. Fundação Serviços de Saúde Pública. Levantamento epidemiológico em saúde bucal: Brasil, zona urbana, 1986. Brasília, Centro de Documentação do Ministério da Saúde, 1988.

17. MIRANDA, V. C. Levantamento do índice de cárie dentária em escolares do ensino primário na cidade de Araraquara. Rev. Farm. Odont., 31:149. $72,1965$.

18. MORAES, N.et al. Características da mortalidade dentária dos primeiros molares permanentes em escolares de Bauru - SP, Brasil. Bol. Ofic. sanit. panamer. 85:541-8, 1978.

19. PEREIRA, C. B. et al. Saúde periodontal, oclusão, desgaste e outras características dentárias nos índios Yanomanis (aborígenes brasileiros). $O r$ todontia, 5:39-54, 1972.

20. SALIBA, N. A. et al. Estado de saúde oral dos escolares da cidade de General Salgado. Estomat. e Cult., 6:73-7, 1972.

21. SALIBA, N. A, et al. Estado de saúde oral dos escolares da cidade de Valparaiso.Estomat e Cult., 9:87-91, 1975.

22. SAlibA, N. A. et al. Prevalência de cárie dentária em escolares da cidade de Penápolis - SP. Rev. gaúcha Odont., 28:287-9, 1980.
23. SILVA, H. C. da et al. Prevalência de cárie dentária em alunos de escolas particulares de Florianópolis, Santa Catarina. Rev. catar. Odont., 10: 20-8, 1983.

24. SOUZA, J. M. P. de et al. Prevalência da cárie dental em Brasília, Brasil. Rev. Saúde públ., S. Paulo, 3: 133 - 40, 1969.

25. TUMAG, A. J. \& PIEDADE, E. F. Cárie dental, doenças periodentais e higiene oral em indígenas brasileiros. Bol. Ofic. sanit. panamer., 64: 103-9, 1968.

26. UCHOA, H. W. et al. Planejamento do serviço odontológico escolar. In: Congresso Odontológico Brasileiro, $9 \%$ Congresso Internacional de Odontologia, 2, Rio de Janeiro, jul. 1965. Rio de Janeiro, 1965. p. $82-96$.

27. VASCONCELOS, M. do C. C. Prevalência de cárie dental em escolares de 7 a 12 anos de idade, na cidade de Araraquara, SP (Brasil), 1979. Rev. Saúde públ., S. Paulo, 16: 317-28, 1982.

28. VERTUAN, V. \& OLIVEIRA, P. A. M. Condiçōes orais em escolares da área deficiente de flúor. Rev. Farm. Odont. Araraquara, 7:113-7, 1973.

29. VERTUAN, V. \& PEREIRA, R. L. da C. C. Prevalência de cárie dentária em escolares de Américo Brasiliense - SP. Rev. Ass. paul. cirurg. Dent., 39: 1325,1985 .

30. VIEGAS, Y. \& VIEGAS, A. R. Prevalência de cárie dental na cidade de Campinas, SP, Brasil, depois de quatorze anos de fluoretação da água de abastecimento público. Rev. Ass, paul. cirurg. dent., 39: 272$82,1985$.

31. VIEGAS, Y. \& VIEGAS, A. R. Prevalência de cárie dental em Barretos, SP, Brasil, após dezesseis anos de fluoretação da água de abastecimento público. Rev. Saúde públ., São Paulo, 22: 25-35, 1988.

Recebido para publicação em 20/9/1989 Reapresentado em 23/4/1990 Aprovado para publicaçāo em 24/4/1990 